\title{
The Effect of Red Pigment and Photo Stabilizers on the Photo Degradation of Polypropylene Films
}

\author{
Rebecca Stéfani de Freitas Brito Cavalcantia, Marcelo Silveira Rabello ${ }^{a}$ ¿(] \\ ${ }^{a}$ Departamento de Engenharia de Materiais, Universidade Federal de Campina Grande, Campina \\ Grande, PB, Brasil
}

Received: November 01, 2018; Revised: February 26, 2019; Accepted: March 09, 2019

\begin{abstract}
The aim of this work was to evaluate the photo degradation of PP films containing photo stabilizers, a ultraviolet absorber and a hindered amine light stabilizer (HALS), and a red pigment. The films were produced by extrusion and exposed to the UV radiation in the laboratory for up to 15 weeks. The results obtained from FTIR, UV-vis and colorimetry showed that the pigment reduced the rate of chemical degradation both in non-stabilized and photo stabilized films, and the influence was more significant for the combination of pigment and HALS. However, the color shift was more evident when the pigment was present, suggesting that this additive may suffer chemical rearrangements during exposure but do not generate free radicals that can initiate degradation of the polymer. The mechanical properties of the films followed the same trend as the other results, but the unexposed films showed a peculiar behaviour, with much higher tensile strength when the pigments were present. X-ray diffraction and DSC analyses suggested that this might be related to differences in crystal structure.
\end{abstract}

Keywords: Degradation, polypropylene, pigment, photo stabilizers.

\section{Introduction}

Polypropylene is one of the most used plastic materials, with a vast number of applications, varying from general propose items to high performance components. The widespread use of this material owes to the good balance of properties, easy processing and reasonable cost. However, when PP based products are exposed to certain conditions like in the presence of ultraviolet radiation their properties deteriorate as a result of oxidative chemical degradation ${ }^{1}$. To overcome this, stabilizers additives like thermal antioxidants, photo stabilizers and metal deactivators must be present, making PP highly dependent on the stabilization system. Even though the cost of product rise when stabilizers are added, they are mandadory for the vast majority of polymers.

Polymer degradation is normally initiated by chemical reactions within the chain or in external molecules like catalyst residues, impurities or additives. The free radicals generated by the initiation reacts with oxygen, give rise to an autocatalytic mechanism of oxidation that results in both chain scission and the formation of chemical groups like carbonyls and hydroperoxides. This mechanism is very well established in the literature, with many studies involving virtually all types of polymers including polypropylene ${ }^{1,2}$. The role of additives in this mechanism is also well described as, for instance, when stabilizers are added to promote a lower rate of degradation. Other types of additives can act either (i) reducing the rate of degradation by limiting the oxygen diffusion into the product or blocking the passage of ultraviolet light ${ }^{3}$ or even acting chemically with the degradation mechanism ${ }^{4}$

*e-mail: marcelo.rabello@ufcg.edu.br or (ii) promoting chemical degradation. The latter occurs when the additive molecules act as source of free radicals or when they contain active sites for chemical reactions ${ }^{6,7}$.

Among the additives that may influence the durability of polymer products, the pigments are frequently cited by academic textbooks and also in technical information given by producers. For example, colour fading by weathering and colour shifting by high processing temperature are criteria for pigment selection, and this is more critical for the case of organic colorants ${ }^{8}$. On the other hand, in some cases pigments may protect the polymer from the photodegradation, like some types of titanium dioxide and carbon black ${ }^{9-13}$. Even though these effects of pigments are extremely important from the practical point of view, the scientific literature gives very little attention to the influence of these additives on the degradation (and stabilization) of polymers. Most of the work was developed on carbon black ${ }^{14,15}$ or white pigments ${ }^{13,16-18}$ and very little with colour products ${ }^{19-21}$. When pigmented products contain photo stabilizers, synergic and antagonic effects may occur $^{22-24}$ and, hence, the need for investigation on this field is even more important. The seek for optimal compositions and the better understanding of the degradation processes of the combined presence of photo stabilizers and pigments are in line with the design of durable products and, hence, fulfilling the expectations of consumers. Again, very little work was published on this topic, which is very surprising owing its importance, especially for polypropylene that is very susceptible to the degradation effects.

This work aims to contribute to this subject, investigating the photodegradation effects of extruded PP. Films produced with a combination of red pigment and two types of photo 
stabilizers - a UV absorber and a hindered amine light stabilizer (HALS) - were exposed in the laboratory for various times and the degradation effects were evaluated by several techniques. The practical importance of this study relies on the need for both UV protection and the colour requirement of final products.

\section{Experimental}

\subsection{Materials}

An industrial grade of polypropylene $\mathrm{H} 301$ produced by Braskem (Brazil), with flow rate of $10 \mathrm{~g} / 10 \mathrm{~min}$ $\left(230^{\circ} \mathrm{C} / 2.16 \mathrm{~kg}\right.$, ASTM D 1238) was used as received. This is general-purpose grade for extrusion and injection moulding containing standard thermal stabilizers to avoid degradation during processing.

The photo stabilizers chosen were a UV absorber 2-(5-chloro-2H-benzotriazole-2-yl)-6-(1,1-dimethylethyl)-4methylphenol, trade name Tinuvin ${ }^{\circledR} 326$, and a high molecular weight HALS, 1,6-Hexanediamine, N,N'-bis(2,2,6,6tetramethyl-4-piperidinyl)-polymer with 2,4,6-trichloro-1,3,5triazine, reaction products with $\mathrm{N}$-butyl-1-butanamine and N-butyl-2,2,6,6-tetramethyl-4-piperidinamine, trade name Chimassorb ${ }^{\circledR} 2020$. Both are recommended for PP. The red pigment was Irgalite Red 2BSP, and azo type produced by Basf and recommended for polyolefins. The manufacturer reports that is has no harmful effect on people and animals.

\subsection{Methods}

\subsubsection{Sample preparation and exposure}

The samples were produced by extrusion in the form of $50 \mu \mathrm{m}$ thick films. The relatively low thickness reduces the influence of heterogeneity in the depth-profile of degradation that occurs with thick sample bars ${ }^{25}$. The polymer and additives were initially melt mixed in an internal mixer (Rheomix 600, Haake) equipped with roller-type rotors at $180^{\circ} \mathrm{C}$ and $60 \mathrm{rpm}$ for 10 minutes. After gridding, the compounds were extruded in an AX Chill-Roll 16 machine with a flat die operating at $180-200^{\circ} \mathrm{C}$ and screw speed of $70 \mathrm{rpm}$. The final amount of additives are given in Table 1.
From the extruded films, samples were cut (before exposure) in the form of strips measuring $10 \mathrm{~cm} \times 1.5 \mathrm{~cm}$, keeping the major dimension as the extrusion direction. The films were then mounted in cardboard supports as shown in Figure 1.

The exposure to ultraviolet radiation was done in the laboratory with Philips R-UVA-TL fluorescent tubes for up to 15 weeks in a constant temperature room set at $30^{\circ} \mathrm{C}$. The distance sample-lamp was adjusted to yield a level of radiation of $0.15 \mathrm{~mW} / \mathrm{cm}^{2}$ at the film surface.

\subsubsection{Characterization}

UV-visible spectroscopy was done in a Perkim Elmer (Lambda 35) equipment using the wavelength range of 200$700 \mathrm{~nm}$. Fourier transform spectroscopy analyses were carried out in Perkin Elmer Spectrum 400 equipment operating in transmission mode. From the spectra, the carbonyl index was calculated as the ratio of the areas under carbonyl peaks (1700-1800 $\mathrm{cm}^{-1}$ ) and a reference peak, which is not affected by photodegradation. The reference peak was taken as the one centred at $2720 \mathrm{~cm}^{-1} 25$.

The changes in colour was determined by the Instrutherm ACR-1023 colour meter equipment using the scales RGB (red, green and blue colour components) and HSL (hue, saturation and lightness). The measurements were done directly on the surface of the films.

Tensile tests were done according to ASTM D882-95 in the Emic DL1000 testing machine using a crosshead speed

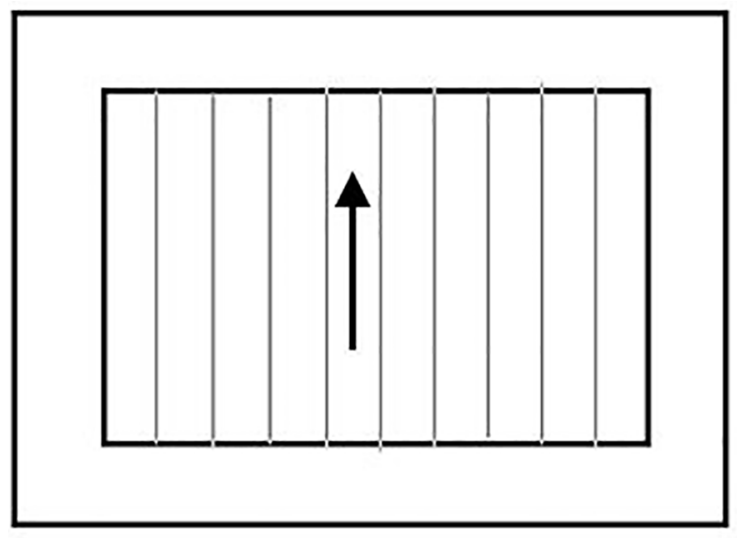

Figure 1. Arrangement for sample exposure. The arrow indicates the extrusion direction

Table 1. Composition of samples and codes used.

\begin{tabular}{lccccc}
\hline \multirow{2}{*}{ Sample } & \multicolumn{2}{c}{ Content (phr) } & Code \\
\cline { 2 - 5 } & $\mathrm{PP}$ & Tinuvin326 & HALS & Pigment & PP \\
Polypropylene & 100 & - & - & - & $\mathrm{PP}_{\mathrm{T}}$ \\
PP/Tinuvin326 & 100 & 0,5 & - & - & $\mathrm{PP}_{\mathrm{H}}$ \\
PP/HALS & 100 & - & 0,5 & - & $\mathrm{PP}_{\mathrm{P}}$ \\
PP/Pigment & 100 & - & - & 0,15 & $\mathrm{PP}_{\mathrm{PT}}$ \\
PP/Pigment/ & 100 & 0,5 & -15 & 0,15 & $\mathrm{PP}_{\mathrm{PH}}$ \\
Tinuvin326 & 100 & - & 0,5 & & \\
PP/Pigment/HALS & & & &
\end{tabular}


of $5 \mathrm{~mm} / \mathrm{min}$ at $23^{\circ} \mathrm{C}$. Selected samples were inspected by scanning electron microscopy (SEM) in Tescan, model Vega3, equipment after covering with a thin layer of gold.

$\mathrm{X}$-ray diffraction analyses were done in a Shimadzu XRD-6000 equipment using $\mathrm{CuK}_{\alpha}$ radiation $(\lambda=1.5418 \AA)$ in the range $2 \theta$ between $7-35^{\circ}$ and scanning rate of $2 \% \mathrm{~min}$. Differential scanning calorimetry (DSC) was done in a Q20 TA Instruments using a heating/cooling rate of $10^{\circ} \mathrm{C} / \mathrm{min}$ under nitrogen purge gas. From the thermograms, the crystallinity was determined as the ratio of the melting enthalpy and the crystals enthalpy, taken as $138 \mathrm{~J} . \mathrm{g}^{-1}$.

\section{Results and Discussion}

\section{$3.1 U V$-visible spectroscopy}

The UV-vis spectra of unexposed and exposed films are shown in Figure 2 for the various compositions. For the neat PP, two absorption bands are relevant: (i) at $222 \mathrm{~nm}$ which is due to a diene group, and (ii) at $267 \mathrm{~nm}$, due to a chromophore triene ${ }^{26}$. Both are supposed to be formed during synthesis and processing, and may act as starting sites for the initiation of chemical degradation during UV exposure ${ }^{2}$. The depletion of these groups by the degradation reactions is the explanation for the reduction of their intensities after prolonged exposures (ca. 15 weeks).

For the films containing HALS $\left(\mathrm{PP}_{\mathrm{H}}\right)$, just one absorption peak was observed, centred at $227 \mathrm{~nm}$, and this is due to the transitions $n, \pi^{*}$ of fractions of 1,3,5-triazine at the oligomer chains of the additive ${ }^{27}$. The spectra sustained almost unchanged even for 15 weeks exposure, showing the high efficiency of this additive in protecting polypropylene, with no noticeable depletion of the stabilizer. The films with the
UV absorber ( $\mathrm{PP}_{\mathrm{T}}$ in Figure 2), showed two main bands, at 315 and $357 \mathrm{~nm}$ which is typical for this photo stabilizer ${ }^{27}$. The absorption of light within this range is the basis of the action of this additive to protect the polymer. During exposure, the intensities of these peaks decrease progressively and vanish at 15 weeks, indicating the drastic reduction of their chemical activity that may be caused by side chemical reactions or by their elimination due to diffusion and/or evaporation effects ${ }^{28}$.

The films containing pigments $\left(\mathrm{PP}_{\mathrm{P}}\right)$ showed a tiny peak at $550-600 \mathrm{~nm}$, hence in the visible region, that is due to colour response of this additive ${ }^{29}$. When these films had photo stabilizers $\left(\mathrm{PP}_{\mathrm{PT}}\right.$ e $\left.\mathrm{PP}_{\mathrm{PH}}\right)$ their behaviour was similar to the non-pigmented ones, suggesting that the pigments did not have a major influence on the extent of degradation insofar as this experimental technique is able to detect. This observation is similar to what was reported for the weathering of pigmented polycarbonate ${ }^{30}$.

\subsection{Fourier transform infrared spectroscopy (FTIR)}

It is well known that the extent of oxidative degradation of polypropylene is evaluated by the presence of carbonyl groups, that are accumulated during exposure. From the infrared spectra, the carbonyl index was calculated as described before and the results are given in Figure 3 for the various compounds under study. The films that were neither photo stabilized or pigmented showed the highest rate of chemical degradation whereas the ones with both HALS and pigments were the least affected. Actually, HALS is considered to be most efficient photo stabilizer ${ }^{8,31}$, a trend also observed by the UV-visible results (Figure 2). A higher stability of PP in presence of both HALS and pigment was observed before ${ }^{29}$.



(a)

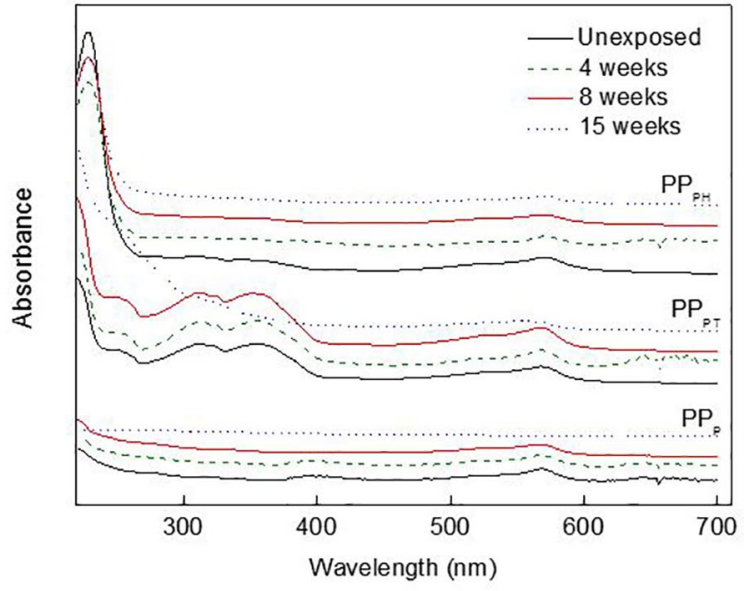

(b)

Figure 2. UV-visible spectra of $\mathrm{PP}$ films (a) neat $\mathrm{PP}$ and photo stabilized $\mathrm{PP}\left(\mathrm{PP}_{\mathrm{T}}\right.$ e $\left.\mathrm{PP}_{\mathrm{H}}\right)$ unexposed and after various exposure times; (b) pigmented $\mathrm{PP}\left(\mathrm{PP}_{\mathrm{P}}\right)$ and $\mathrm{PP}$ with a combination of pigment and stabilizer $\left(\mathrm{PP}_{\mathrm{PT}} \mathrm{e} \mathrm{PP}_{\mathrm{PH}}\right)$. 


\subsection{Colorimetry}

The measurements of colour parameters and the effects of UV exposure are given in Figure 4 for the RGB scale. These results indicate the variations of the red, green and blue colour components. Colour fading during the use of polymer products is one of the main reasons for shortening lifetime and may occur due to (i) the formation of chromophore groups, like carbonyl and hydroperoxide, within the polymer molecule ${ }^{32}$; (ii) surface cracking, that leads to the reflection of all wavelength and thus reduces the selectivity in light absorption and causes whitening ${ }^{14}$; and (iii) changes in pigment molecule chemical structure that lead to colour shifting ${ }^{8}$. The combination of these effects is shown in the variation of RGB colour components of Figure 4. A significant change in RGB values is observed especially for neat PP and its combinations with UV absorber and pigment. On the other hand, the most stable sample was the one with HALS, which is consistent to the previous results. The values obtained with samples containing pigment was hugely changed with exposure, and the effects were more

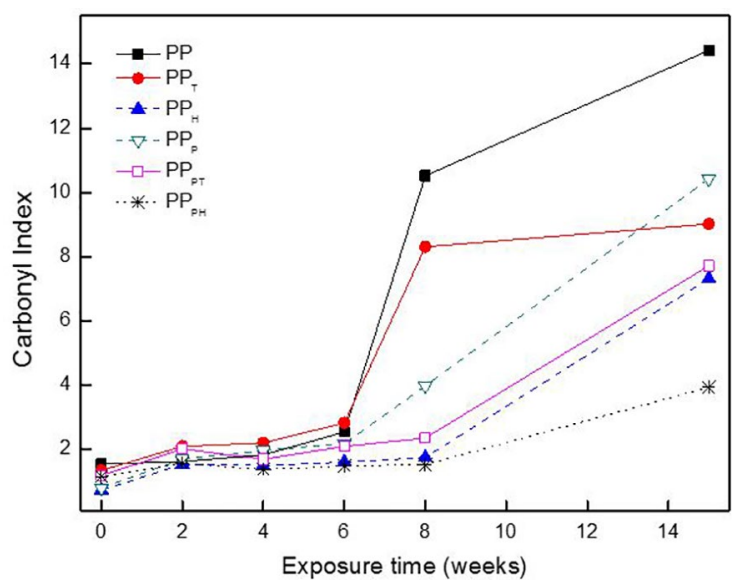

Figure 3. Carbonyl as a function of exposure time for the various films under study.

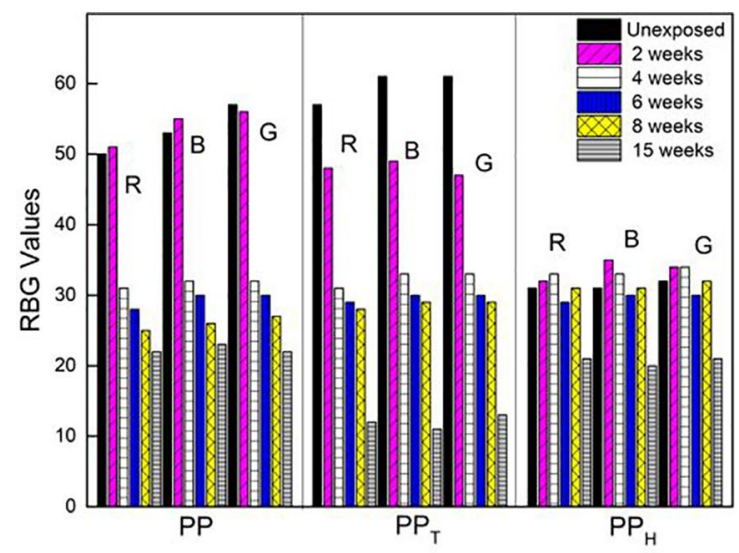

(a) significant when pigments were combined with HALS in comparison with HALS only. This is different from what was observed by carbonyl index results and may be explained on the basis for each type of measurement. Carbonyl index indicates the extent of chemical degradation, whereas colorimetry evaluates the change in sample colour, which can may occur even without oxidative chemical reactions. It is well known that organic pigments, like the one used here, may suffer some molecular rearrangements during exposure and this changes the light absorption characteristics, leading to a colour shift ${ }^{33}$ even if no chemical reactions take place. The colours of the compounds with pigments, therefore, are much more sensitive to the exposure effects. Another explanation for the colour shift in pigmented samples would be their elimination after migration to the film surface ${ }^{19}$.

Figure 5 shows the results for HSL scale - hue, saturation and lightness. This type of measurement is used for quality control in industry though not much in scientific papers but, due to the great practical importance of evaluating the visual aspects of a weathered product, these results were included here. Hue indicates the actual colour that starts from a value of zero for a standard red. Saturation can be understood as similar to contrast, or colour purity; a minimal value correspond to a shade of grey and the maximum value to a pure colour. The lightness is a measurement of the relative white or black in a colour. For the films under study, the values of $\mathrm{H}$ increased with exposure, as a consequence of the progressive whitening. In pigmented samples, this increase was more evident only at 15 weeks exposure since the red colour overcomes the whitening effect. The values of saturation and lightness showed some decay with exposure for the non stabilized films, whereas for the photo stabilized ones, these parameters were more stable, even after prolonged exposures.

\subsection{Surface cracking and mechanical properties}

Cracks on the surfaces of the extruded films did not appear at 8 weeks exposure, even for the non stabilized ones.

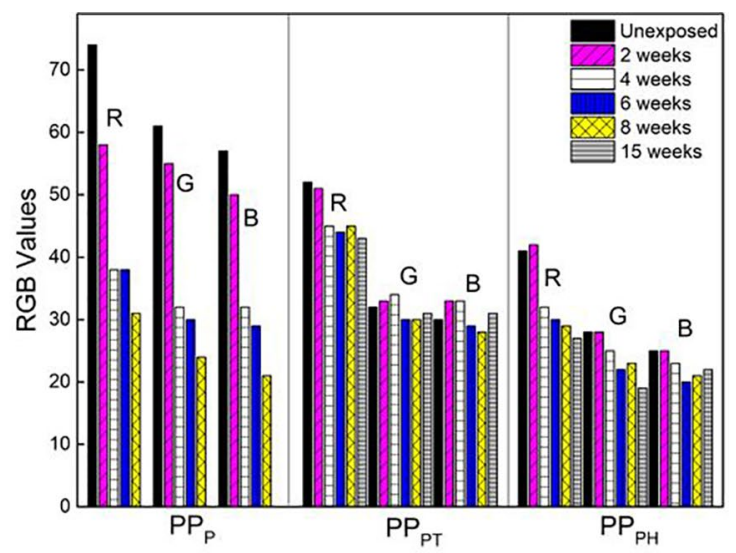

(b)

Figure 4. RGB values of the various films before and after exposure for the non-pigmented (a) and pigmented (b) samples. 


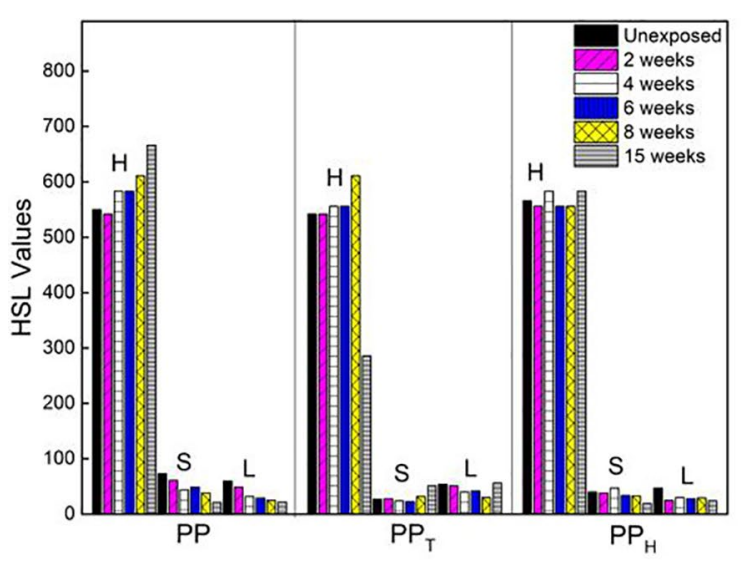

(a)

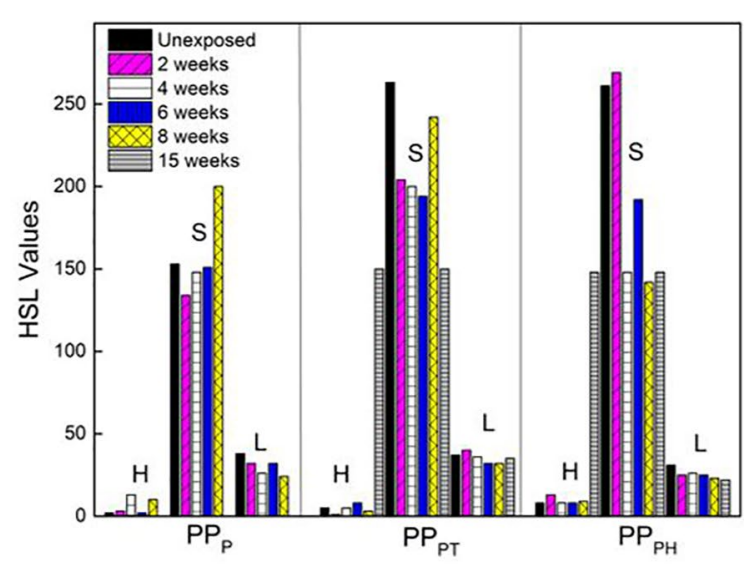

(b)

Figure 5. HSL values of the various films before and after exposure for the non-pigmented (a) and pigmented (b) samples.

At 15 weeks, the films that did not contain photo stabilizers were so damaged that collapsed completely during handling and, hence, their surfaces could not be shown here. Figure 6 gives examples of the stabilized films exposed for 15 weeks, obtained by SEM before tensile testing. It is clear that when HALS was present the state of deterioration is much lower, which is consistent with other measurements shown so far. The formation of surface cracks during polymer exposure without external stresses is due to the increase in crystallinity caused by the rearrangement of molecule segments released by chain scission events. This is called chemi-crystallization and was detailed described by one of the authors ${ }^{34}$.

The values of tensile strength are given in Figure 7 for the various compounds under study. For the unexposed films, the photo stabilizers did not change this property, but the presence of pigments in PP and PP with UV absorber caused a significant increase in strength. The first explanation for this behaviour would be the crystal nucleating action of the pigment that could lead to an increase in crystallinity ${ }^{35,36}$. However, measurements done by DSC (Table 2) showed that, apparently, this did not occur with the samples studied here, as noted by the values of degree of crystallinity and crystallization temperature. On the other hand, the analyses done by X-ray diffraction (Figure 8) revealed a significant difference in crystal structure. The films with pigment showed the standard monoclinic crystal lattice ${ }^{37}$, with peaks at $14^{\circ}$, $16.8^{\circ}, 18.5^{\circ}, 21.8^{\circ}, 25.4^{\circ}$ whereas the neat PP had only two broad peaks at $\sim 15^{\circ}$ and $21^{\circ}$. This crystal structure seems to be a type of mesomorphic phase of $\mathrm{PP}^{38,39}$, formed during the extrusion process. This phase has an intermediate estate of order, between the amorphous and the crystalline and, as a result, shows much lower molecular packing in comparison to the standard monoclinic structure and, hence, lower tensile strength. In addition, as a result of a lower packing, the Young's modulus of neat PP was much lower than the one for the film containing the pigment (850MPa and 1400MPa, respectively). Currently, we do not have a complete explanation for this behaviour that could be the subject of a deeper investigation, but it is possible that the presence of pigments caused a nucleating effect under processing conditions, generating a more stable crystal structure. This nucleating effect was not observed during DSC experiment due to the cooling condition, which is rather different from that applied after extrusion. The mesomorphic phase is unstable and can be transformed during heating, as shown in the thermograms of Figure 9 with an exothermic hump at $80-120^{\circ} \mathrm{C}$. This fact also changes the crystallinity measurements by DSC, which takes into account only the endothermic melting peak. This effect seems not to happen with the same extent when HALS is present and the only explanation we offer is a kind of interaction or solubility between the two additives that reduces the nucleating activity of the pigment. Again, this deserves further investigation.

The effect of UV exposure on tensile strength, also given in Figure 7, showed that the neat PP was the most sensitive to the degradation effects, with a significant decay at 8 weeks. At 15 weeks, the films were so fragile that could not even be tested. The ones containing UV absorber showed a prolonged stability whereas those with HALS had just a small decay at 15 weeks. This is consistent with the experiments that evaluated the extent of chemical degradation (Figure 3) and reflected the higher efficiency of HALS for UV stabilization of PP. The films containing pigment and photo stabilizers had a higher performance, as observed also by other characterization techniques.

The results for maximum elongation (Figure 10) showed that the presence of photo stabilizers did not change the values for the unexposed films but when pigments were added, a reduction in this property possibly because of the change in crystal lattice as discussed before. The elongation is considered the mechanical property most sensitive to the degradation effects ${ }^{25}$ and the results of Figure 10 showed this, with the films containing both HALS and pigments presenting the most stable behaviour. 

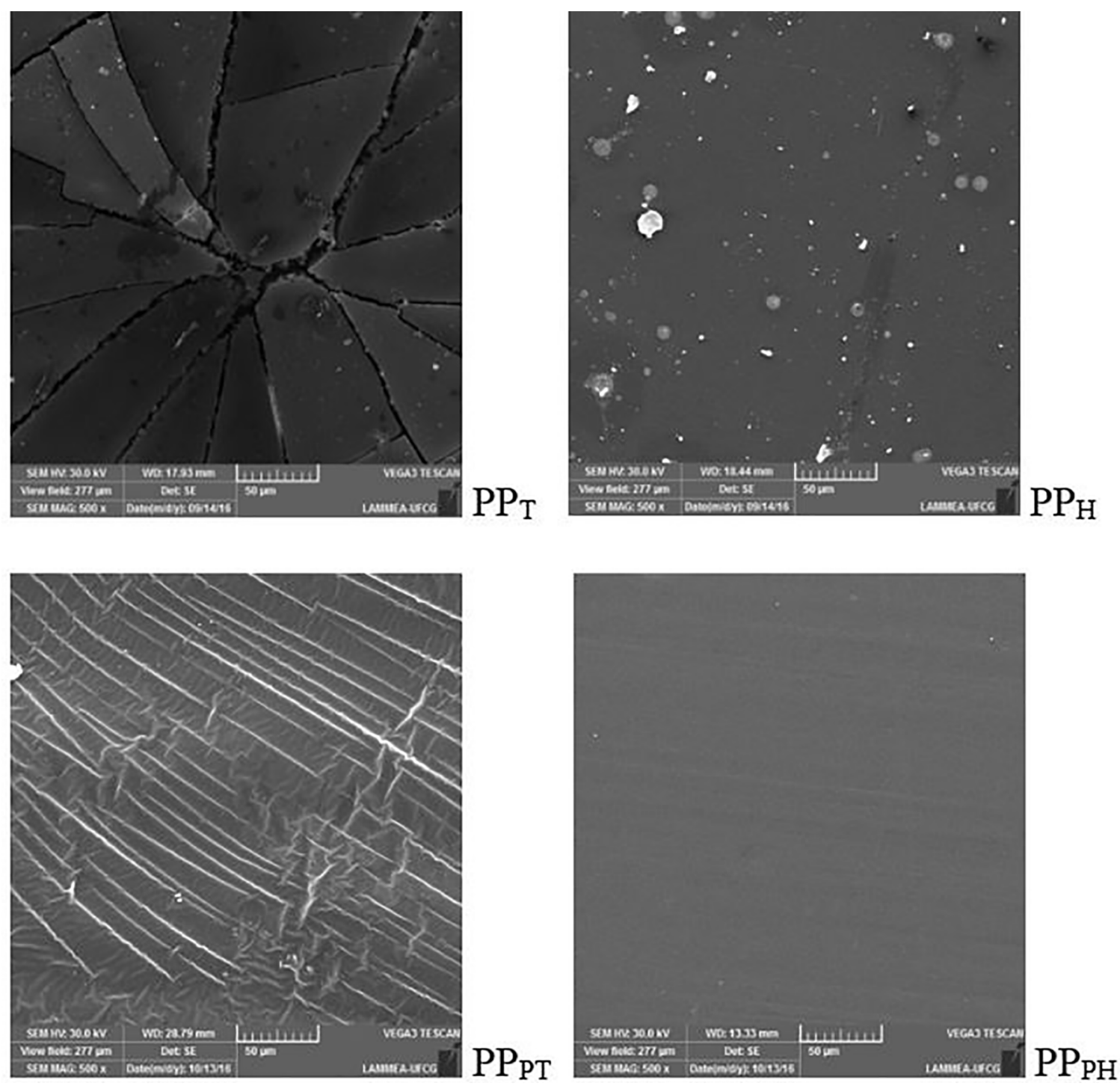

Figure 6. Scanning electron microscopy of films surfaces after 15 weeks exposure.

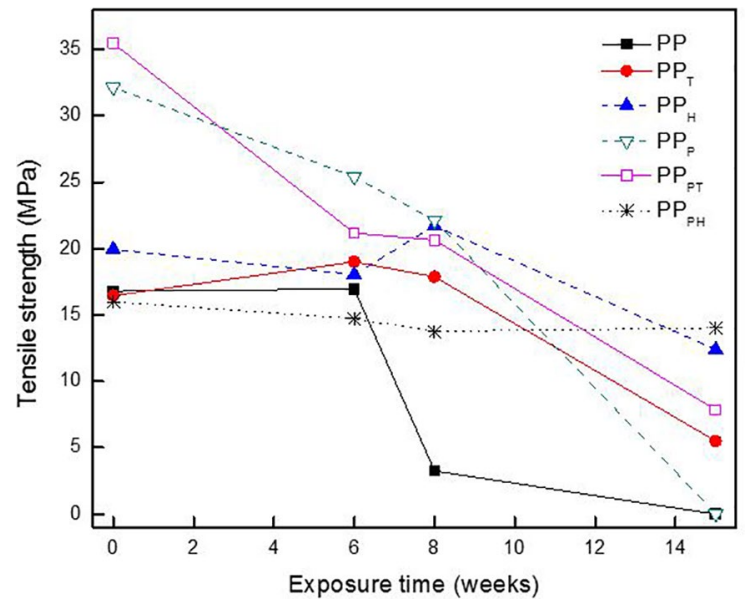

Figure 7. The effect of exposure and additives on tensile strength of polypropylene.
Table 2. DSC data for neat and pigmented PP.

\begin{tabular}{lccc}
\hline Sample & $\mathrm{T}_{\mathrm{m}}\left({ }^{\circ} \mathrm{C}\right)$ & $\mathrm{T}_{\mathrm{c}}\left({ }^{\circ} \mathrm{C}\right)$ & $\mathrm{X}_{\mathrm{c}}(\%)$ \\
\hline PP & 161,7 & 119,0 & 42,9 \\
PPP & 164,5 & 120,2 & 40,5 \\
\hline
\end{tabular}

\section{Conclusions}

The results of this work showed that when photo stabilizers like Tinuvin 326 (UV absorber) and Chimassorb 2020 (HALS) are present, the lifetime of PP films are increased, especially for the HALS additive, with a lower rate of degradation and much better mechanical properties after 15 weeks of UV exposure in the laboratory. For example, the tensile strength raised from 0 for the non-stabilized films to nearly $15 \mathrm{MPa}$ for the ones containing HALS. The presence 




Figure 8. X-ray diffractograms of neat and pigmented PP.

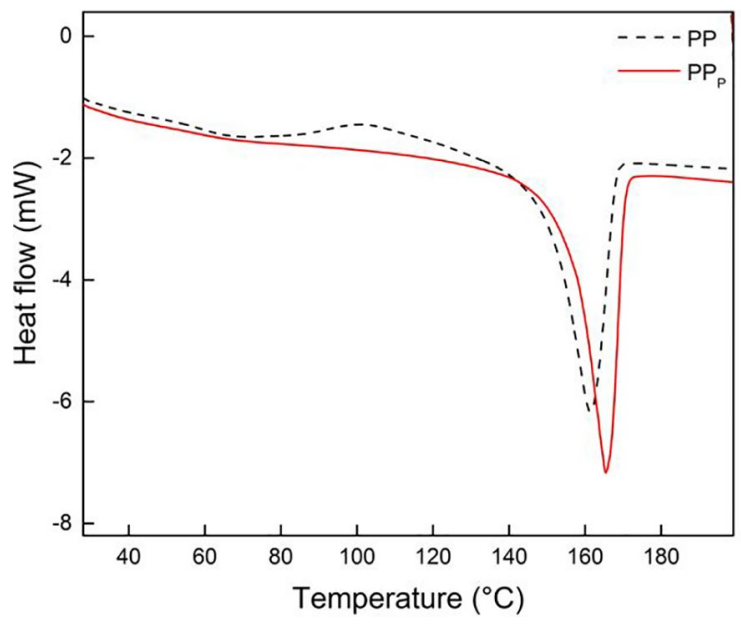

Figure 9. DSC thermograms of neat and pigmented PP.

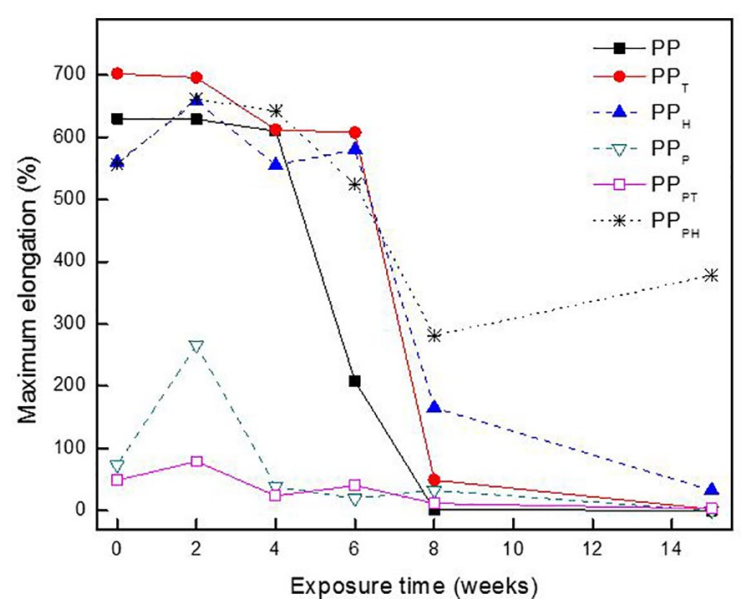

Figure 10. The effect of exposure and additives on maximum elongation of polypropylene. of red pigment improved the UV stability when evaluated by infrared and UV-visible spectroscopy but showed a higher colour shift, even when combined with HALS. The mechanical properties followed the same trend of the extent of chemical degradation with films containing both HALS and pigment the most resistant after prolonged exposure. However, for the unexposed condition, the films containing pigment showed a much higher tensile strength and Young's modulus and this type of behaviour was related to the crystal structure, according to preliminary results obtained by X-ray diffraction and DSC. These analyses suggested that crystal structure of extruded films with pigment was monoclinic whereas a mesomorphic structure was formed when the pigment was not present.

\section{Acknowledgements}

The authors are indebted to $\mathrm{CNPq}$, Brazilian funding agency, for financial support and to CertBio (UFCG) for the FTIR analyses.

\section{References}

1. Allen NS. Degradation and Stabilisation of Polyolefins. London: Elsevier Science; 1983.

2. Carlsson DJ, Wiles DM. The Photooxidative Degradation of Polypropylene. Part I. Photooxidation and Photoinitiation Processes. Journal of Macromolecules Science, Part C. 1976;14(1):65-106

3. Rabello MS, White JR. Photodegradation of talc-filled polypropylene. Polymer Composites. 1996;17(5):691-704.

4. Mistretta MC, Botta L, Vinci AD, Ceraulo M, La Mantia FP. Photo-oxidation of polypropylene/graphene nanoplatelets composites. Polymer Degradation and Stability. 2019;160:3543.

5. Zaikov GE, Polishchuk AY. New aspects of the problem of the ageing and stabilisation of polymers. Russian Chemical Reviews. 1993;62(6):603-623.

6. Salah HB, Ben Daly H, Denault J, Perrin F. UV degradation of clay-reinforced polypropylene nanocomposites. Polymer Engineering and Science. 2016;56(4):469-478.

7. Ramos Filho FG, Mélo TJA, Rabello MS, Silva SML. Thermal stability of nanocomposites based on polypropylene and bentonite. Polymer Degradation and Stability. 2005;89(3):383-392.

8. Zweifel H. Plastics Additives Handbook. Munich: Hanser; 2001.

9. White JR, Shyichuk AV, Turton TJ, Syrotynska ID. Effect of stabilizer and pigment on photodegradation of polypropylene as revealed by macromolecule scission and crosslinking measurements. Polymer Degradation and Stability. 2006;91(8):1755-1760. 
10. Delprat P, Gardette JL. Analysis of photooxidation of polymer materials by photoaccoustic fourier transform infra-red spectroscopy. Polymer. 1993;34(5):933-937.

11. Jin CQ, Christensen PA, Egerton TA, Lawson EJ, White JR. Rapid measurement of polymer photo-degradation by FTIR spectrometry of evolved carbon dioxide. Polymer Degradation and Stability. 2006;91(5):1086-1096.

12. Fechine GJM, Rabello MS, Souto Maior RM, Catalani LH. Surface characterization of photodegraded poly(ethylene terephthalate). The effect of ultraviolet absorbers. Polymer. 2004;45(7):2303-2308.

13. Curcio MS, Canela MC, Waldman WR. Selective surface modification of TiO2-coated polypropylene by photodegradation. European Polymer Journal. 2018;101:177-182.

14. Maia DRJ, Balbinot L, Poppi RJ, De Paoli MA. Effect of conducting carbon black on the photostabilization of injection molded poly(propylene-co-ethylene) containing $\mathrm{TiO}_{2}$. Polymer Degradation and Stability. 2003;82(1):89-98.

15. Horrocks AR, Mwila J, Miraftab M, Liu M, Chohan SS. The influence of carbon black on properties of orientated polypropylene 2. Thermal and Photodegradation. Polymer Degradation and Stability. 1999;65(1):25-36.

16. Gil-Castell O, Badia JD, Teruel-Juanes R, Rodriguez I, Meseguer F, Ribes-Greus A. Novel silicon microparticles to improve sunlight stability of raw polypropylene. European Polymer Journal. 2015;70:247-261.

17. Butylina S, Martikka O, Kärki T. Weathering properties of coextruded polypropylene-based composites containing inorganic pigments. Polymer Degradation and Stability. 2015;120:10-16.

18. Li G, Wang F, Liu P, Gao C, Ding Y, Zhang S, et al. Antioxidant functionalized silica-coated $\mathrm{TiO} 2$ nanorods to enhance the thermal and photo stability of polypropylene. Applied Surface Science. 2019;476:682-690.

19. Peng Y, Guo X, Cao JZ, Wang W. Effects of Two Staining Methods on Color Stability of Wood Flour/Polypropylene Composites During Accelerated UV Weathering. Polymer Composites. 2017;38(6):1194-1205.

20. Hulme A, Mills NJ. The Analysis of Weathering Tests on Industrial Helmets Moulded from Coloured Polyethylene. Plastics, Rubber and Composites Processing and Applications. 1994;22(5):285-303.

21. Butylina S, Hyvärinen M, Kärki T. Weathering of wood-polypropylene composites containing pigments. European Journal of Wood and Wood Products. 2012;70(5):719-726.

22. Gesenhues U, Hocken J. TiO2 pigment structure and kinetics of PVC weathering. Journal of Vinyl \& Additive Technology. 2000;6(2):80-87.

23. Kikkawa K. New Developments in polymer photostabilization. Polymer Degradation and Stability. 1995;49(1):135-143.

24. Vaillant D, Lacoste J, Lemaire J. Stabilization of isotactic polypropylene. Problems bound to the interactions of stabilizers with pigments and fillers. Journal of Applied Polymer Science. 1997;65(3):609-615.
25. Rabello MS, White JR. The role of physical structure and morphology on the photodegradation behaviour of polypropylene. Polymer Degradation and Stability. 1997;56(1):55-73.

26. Kawanishi S, Shimizu Y, Sugimoto S, Suzuki N. Irradiation effects of excimer laser radiation and electron-beam on polypropylene and ethylene-tetrafluoroethylene copolymer films. Polymer. 1991;32(6):979-983.

27. Scoponi M, Cimmino S, Kaci M. Photo-stabilisation mechanism under natural weathering and accelerated photo-oxidative conditions of LDPE films for agricultural applications. Polymer. 2000;41(22):7969-7980.

28. Richaud E, Fayolle B, Verdu J. Polypropylene stabilization by hindered phenols - Kinetic aspects. Polymer Degradation and Stability. 2011;96(1):1-11.

29. Ahmadi Z, Kish MH, Freeman H, Kotek R, Katbab AA. Photostability of isotactic polypropylene containing monoazo pigment. Journal of Applied Polymer Science. 2008;108(5):29502957.

30. Saron C, Felisberti MI, Zulli F, Giordano M. Influence of diazo pigment on polycarbonate photodegradation. Journal of Applied Polymer Science. 2008;107(2):1071-1079.

31. Rabello MS, de Paoli MA. Aditivação de Termoplásticos. São Paulo: Artliber; 2013

32. Zaikov GE. The Current State of Polymer Aging and Stabilization. International Journal of Polymeric Materials and Polymeric Biomaterials. 1992;16(1-4):1-30.

33. Moura JCVP, Oliveira-Campos AMF, Griffiths J. The effect of additives on the photostability of dyed polymers. Dyes and Pigments. 1997;33(3):173-196.

34. Rabello MS, White JR. Crystallization and Melting Behaviour of Photodegraded Polypropylene - 1. Chemi-Crystallization. Polymer. 1997;38(26):6379-6387.

35. Varga J. Crystallization, Melting and Supermolecular Structure of Isotactic Polypropylene. In: Karger-Kocsis J, ed. Polypropylene: Structure, Blends and Composites. Volume 1. London: Chapman \& Hall; 1995. p. 56-115.

36. Garbarczyk J, Paukszta D. Influence of additives on the structure and properties of polymers. Colloid \& Polymer Science. 1985;263(12):985-990.

37. Trotignon JP, Lebrun JL, Verdu J. Crystalline Polymorphism and Orientation in Injection-Moulded Polypropylene. Plastics and Rubber Processing and Applications. 1982;2(3):247-251.

38. Funaki A, Kanai T, Saito Y, Yamada T. Analysis of contributing factors to production of highly transparent isotactic polypropylene extrusion sheets. Part I. Polymer Engineering and Science. 2010;50(12):2356-2365.

39. Cohen Y, Saraf RF. A direct correlation function for mesomorphic polymers and its application to the 'smectic' phase of isotactic polpropylene. Polymer. 2001;42(13):5865-5870. 